\section{Assessing Micronutrient Adherence after Bariatric Surgery: An Exploratory Study}

Keywords: Micronutrients; Adherence; Bariatric surgery; Roux-en-Y gastric bypass; Sleeve gastrectomy; Calcium; Iron

\begin{abstract}
Background: Micronutrient supplementation is a lifelong requirement following bariatric procedures in order to minimize longterm complic ations. However, little is known about patient adherence to postoperative micronutrient supplementation and the bamiers for non-adherence.

Objective: An exploratory study to examine self-reported adherence to micronutrient supplementation after bariatric surgery, investigate bamiers to adherence, and identify factors affecting supplement purchase.
\end{abstract}

Setting: Online survey posted in two community support forums for bariatric surgery patients.

Methods: A survey was developed and a imed to collect bariatric surgery patient's demographic information, surgical history, baseline health; and assess a dherence to mic ronutrient supplements, purc hase, and bamiers to adherence.

Results: One hundred fifty four bariatric surgery recipients responded to the survey. The self-reported adherence rate for micronutrient supplementation ranged between $68.4 \%$ and $100 \%$. Calcium and iron supplements had the lowest adherence rate. Forgetting to take the supplement and experiencing side effects were the two leading bamiers to adherence $(41.3 \%$ and $20.6 \%$ respectively). Other bamiers included costs and palatability of the products. Ninetytwo percent of the study cohort purchased their supplements in local stores or through the intemet. Having a bariatric branding on the product was the leading influencing factor in guiding purchases, followed by recommendations from care providers.

Conclusions: Our study suggests that micronutrient nonadherence is a concem after bariatric surgery and may pose risks for long-term complications. These findings have provided the information to help design future investigations aimed to improve mic ronutrient supplement a dherence, and maximize the long-term sa fety of ba ria tric surgery and other surgeries of the gastrointestinal tract.

\section{Abbreviations}

AUC: Area Under the Concentration-time curve; BMI: Body Mass Index; GI: Gastrointestinal; LAGB: Laparoscopic Adjustable Gastric Banding; MCS: Mental Component Summary; PCS: Physical Component Summary; RYGB: Roux-en-Y Gastric Bypass; SG: Sleeve Gastrectomy

\section{Introduction}

The importance of postoperative micronutrient supplementation is widely recognized by researchers and clinicians in bariatric surgery. Nutrition screening and micronutrient supplementation are part of the established clinical guidelines for the postoperative care of bariatric

\section{Journal of}

Obesity and

Bariatrics

\author{
Lingtak-Neander Chan ${ }^{1,2 *}$, Qianxiong Zheng ${ }^{2}$ and \\ Tiana Colovos ${ }^{1,3}$ \\ ${ }^{1}$ Department of Pharmacy, School of Pharmacy, University of \\ Washington, Washington, USA \\ ${ }^{2}$ Graduate Program in Nutritional Sciences, School of Public Health, \\ University of Washington, Washington, USA \\ ${ }^{3}$ Department of Nutritional Services, University of Washington \\ Medical Center, Washington, USA \\ *Address for Correspondence \\ Lingtak-Neander Chan, Pharm.D, BCNSP, Department of Pharmacy, \\ School of Pharmacy, 1959 NE Pacific Street, Box 357630, University of \\ Washington, Seattle, WA 98195, USA, Tel: (206) 543-7987; Fax: (206) \\ 543-3835; E-mail: neander@u.washington.edu \\ Submission: 23 September 2015 \\ Accepted: 30 September 2015 \\ Published: 05 October 2015 \\ Copyright: (c) 2015 Chan LN, et al. This is an open access article \\ distributed under the Creative Commons Attribution License, which \\ permits unrestricted use, distribution, and reproduction in any medium, \\ provided the original work is properly cited. \\ Reviewed \& Approved by: Dr. Francesco Saverio Papadia, \\ Assistant Professor of Surgery, University of Genoa School of Medicine, \\ Italy
}

patients [1]. Despite routine micronutrient supplementation, studies continue to show that micronutrient deficiencies remain common in bariatric surgery patients [2-4]. The reasons for the occurrence of micronutrient deficiencies in these patients are likely multifactorial which may include non-adherence to the micronutrient regimens, misunderstanding of the supplement regimens by the patient, and using micronutrient supplements that do not meet the patient's needs.

Unlike medication adherence, which can be evaluated based on refill frequency and refill pattern (i.e., whether refills are delayed) from pharmacy records, adherence to micronutrient supplements is difficult to assess since these are over-the-counter dietary supplements with no available "refill" records. The research in this area is also lacking. Modi et al. studied short-term adherence to multivitamin in 41 adolescent patients with Roux-en-Y gastric bypass (RYGB) and sleeve gastrectomy (SG) in a prospective observational study over a 6-month period. The mean self-reported adherence rate was $88.4 \%$ and $78.6 \%$ at the $1-$ and 6 -month postoperative clinic visits, respectively, whereas the electronic monitoring system that captured the number and time of bottle opening logged an adherence rate of $37.4 \%$ and $27.1 \%$ during the same time intervals [5]. Similar studies have not been conducted in adult bariatric patients. Additionally, no studies have attempted to gain insight into patients' perspectives in whether they understand the provider's instructions, their perceived value of micronutrient supplementations, and barriers to non-adherence. Furthermore, factors influencing bariatric patients' preference and the driving factors to the purchase of micronutrient supplement products can be relevant to supplementation adherence and treatment outcomes. These issues have received little research attention. 
Citation: Chan LN, Zheng Q, Colovos T. Assessing Micronutrient Adherence after Bariatric Surgery: An Exploratory Study. J Obes Bariatrics. 2015;2(2): 8.

Since committing to a lifelong micronutrient supplementation is an essential component of post-bariatric care, an understanding to the above factors may provide important information to maximize long-term success of bariatric surgery. We therefore conducted an exploratory study aimed to: 1) examine self-reported adherence to recommended micronutrient supplementation in patients who had bariatric surgery; 2) investigate patients' perceived barriers to supplement adherence; 3 ) identify factors that may affect bariatric patients' supplement purchase, choice and adherence.

\section{Methods}

\section{Study design and population}

An online survey was developed to assess patient self-reported adherence to micronutrient supplementation and barriers to adherence after their bariatric surgery. The survey was first beta-tested by 5 bariatric surgery patients, who provided feedback to the research team regarding the clarity of the questions and time spent to complete the survey. The finalized version of the survey was administered via SurveyMonkey.com (LLC, Palo Alto, California), an online survey and quiz tool. Upon agreeing to participate in the study at entrance to the online survey, the respondents were directed to complete a threepart questionnaire that collects: 1) demographic information and history related to the patient's bariatric surgery; 2) information on adherence and barriers to micronutrient supplementation, and factors affecting supplement purchase and choice; and 3) an SF- $12^{\circ}$ Health Survey measuring respondent's functional health and well-being. The survey was posted on two online community support forums for RYGB and SG which belong to a weight loss surgery social network (www.bariatricpal.com) with over 240,000 members. Approval of the director of the community support forum was obtained before the survey was published on the website. The research has been approved by Institutional Review Board of our institution under the Exempt category.

\section{Survey content}

Demographic information: Patients were asked to provide information regarding their sex, age, race, current employment status, family income, health insurance status, and surgical history. Height and current weight were collected to calculate body mass index (BMI).

Self-reported adherence: Questions were asked regarding whether they were instructed by their providers to take micronutrient supplementation and if so, whether they remembered the specific regimens, including type and quantity. Patients were also asked about the actual micronutrient regimens they were currently taking. Based on the published guidelines [1] and our experience, specific information about the following micronutrients was included: multivitamin and minerals, calcium, iron, folic acid, thiamin, vitamin $\mathrm{B} 12$ products, vitamin $\mathrm{C}$, and vitamin $\mathrm{D}$. A patient was considered adherent if he/she was taking the supplements exactly as they were instructed. A patient was considered non-adherent if the actual intake, either the amount or frequency, was less than the recommendation as determined by his/her provider. Adherence rate was calculated using the total number of patients who were adherent to their regimens divided by the total number of respondents who remembered both the recommended amount and their current intake of the supplements. For patients who were unable to recall either the amount as recommended by their providers or the actual amount there were taking, their responses were not included in the calculation of adherence rate.

Barriers to adherence: Potential barriers listed for patients to select included forgetting, affordability, side effects, difficulty in finding the recommended supplements, and confusion about care provider's instructions. Patients could also enter additional barriers as free text if it was not included on the list.

Supplement purchase and choice: These questions collected information regarding the factors that influenced the patient's preference and purchase of micronutrient supplements.

Health-related quality of life analysis: In order to determine how the quality of life and functional status of our cohort compare to the general population in the U.S., we used the 12 questions from the 12-item Short Form (SF-12') Health Survey (Optum Inc., Eden Prairie, MN) to evaluate patient's physical and mental functioning during the past 4 weeks from their point of view. A score of $0=$ lowest level of health and $100=$ highest level of health and it is normalized so that a score of 50 is the average for the U.S. population. Physical Component Summary (PCS) measure and Mental Component Summary (MCS) measure scored from the SF-12 survey provided an overview of a respondent's health status from both a physical and a mental health perspective.

\section{Statistical analyses}

Descriptive statistics expressed as percentage, median, mean, and standard deviations were used for qualitative and quantitative survey. General characteristics were compared among patients with different bariatric procedures by using unpaired Student's $t$-test and $\chi^{2}$ test for parametric and categorical data, respectively. The SF-12 PCS and MCS measures were computed and standardized to a mean of 50 and a standard deviation of 10 by the Quality Metric Health Outcomes Scoring Software 4.5 in relation to 2009 U.S. general population norms; that is, scores obtained above and below 50 could be interpreted as being above and below the average, respectively, in the 2009 U.S general population [6]. A $p$ value of $<0.05$ was considered as statistically significant. Statistical analyses were performed using Stata (version 11, 2009, Stat Corp LP). We estimated that about 250 cases of bariatric surgical procedures are performed annually in an average high-volume bariatric surgery center. With a confidence interval of $95 \%$ and margin of error of $5 \%$, we need about 152 respondents.

\section{Results}

\section{Patient characteristics}

Between June 2 and September 24, 2014, a total of 161 patients accessed the link to the survey. One hundred fifty eight patients (98\%) accepted the online consent to proceed with the survey. Four respondents who had initially accepted the consent did not complete the survey. Consequently, 154 bariatric surgery patients were included in the final analysis. Among these respondents, 95 (61.7\%) underwent SG, 52 (33.8\%) received RYGB, and 3 (1.9\%) had laparoscopic adjustable gastric banding (LAGB). Since the number of 
Citation: Chan LN, Zheng Q, Colovos T. Assessing Micronutrient Adherence after Bariatric Surgery: An Exploratory Study. J Obes Bariatrics. 2015;2(2): 8.

\section{ISSN: $2377-9284$}

patients with LAGB is very small, their results were not included in the final analysis. Additionally, 4 patients did not specify the type of the surgery they had and their responses therefore were also excluded in the final analysis, which included 147 respondents.

The demographic and clinical characteristics of the patients were summarized in Table 1 . The majority of the patients were female (90.5\%), Caucasian $(82 \%)$, between 30 to 59 years of age $(87 \%)$ with a mean current postoperative BMI of $35.3 \pm 7.4 \mathrm{~kg} / \mathrm{m}^{2}$. They were predominantly $(72 \%)$ employed at the time of the survey and (80\%) had private health insurance. The median range of annual household income was $\$ 75,000$ to $\$ 99,999$. Eighty-five percent of the respondents had their surgery within the last twelve months. The average SF-12 PCS score was 51.2 \pm 10.1 , and the average MCS score was 52.4 \pm 8.0 . The results suggest that the well-being of our cohort is

Table 1: Characteristics of bariatric surgery patients who have completed the survey.

\begin{tabular}{|c|c|c|c|c|}
\hline Characteristic & Total $(n=147)$ & $\begin{array}{l}\text { RYGB } \\
(n=52)\end{array}$ & $\begin{array}{c}\text { SG } \\
(n=95)\end{array}$ & P value \\
\hline Age, y, n (\%) & & & & 0.97 \\
\hline $30-39$ & $37(25.2)$ & $13(25.0)$ & $24(25.3)$ & \\
\hline $40-49$ & $54(36.7)$ & $19(36.5)$ & $35(36.8)$ & \\
\hline$\geq 60$ & $11(7.5)$ & $4(7.7)$ & $7(7.4)$ & \\
\hline Sex, n (\%) & & & & 0.58 \\
\hline Female & $133(90.5)$ & $48(92.3)$ & $85(89.5)$ & \\
\hline Male & $14(9.5)$ & $4(7.7)$ & $10(10.5)$ & \\
\hline Current BMI, kg/m², mean + SD & $35.3(7.4)^{\mathrm{a}}$ & $35.1(7.3)^{b}$ & $35.5(7.4)$ & 0.75 \\
\hline Caucasian & $121(82.3)$ & $39(75.0)$ & $82(86.3)$ & 0.76 \\
\hline Latino/Hispanic & $11(7.5)$ & $5(9.6)$ & $6(6.3)$ & \\
\hline African-American & $9(6.1)$ & $4(7.7)$ & $5(5.3)$ & \\
\hline Asian/Pacific islander & $3(2.0)$ & $2(3.8)$ & $1(1.1)$ & \\
\hline Native American/American Indian & $2(1.4)$ & $1(2.0)$ & $1(1.1)$ & \\
\hline Other & $1(0.7)$ & 0 & $1(1.1)$ & \\
\hline Prefer not to respond & $3(2.0)$ & $1(2.0)$ & $2(2.1)$ & \\
\hline Employment status, n (\%) & & & & 0.80 \\
\hline Unemployed & $24(16.3)$ & $7(13.5)$ & $17(17.9)$ & \\
\hline Employed & $106(72.1)$ & $38(73.1)$ & $68(71.6)$ & \\
\hline Retired & $16(10.9)$ & $6(11.5)$ & $10(10.5)$ & \\
\hline Less than $\$ 20,000$ & $9(6.1)$ & $4(7.7)$ & $5(5.3)$ & \\
\hline$\$ 20,000$ to $\$ 34,999$ & $14(9.5)$ & $6(11.5)$ & $8(8.4)$ & \\
\hline$\$ 35,000$ to $\$ 49,999$ & $11(7.5)$ & $5(9.6)$ & $6(6.3)$ & \\
\hline$\$ 50,000$ to $\$ 74,999$ & $30(20.4)$ & $7(13.5)$ & $23(24.2)$ & \\
\hline$\$ 75,000$ to $\$ 99,999$ & $33(22.4)$ & $10(19.2)$ & $23(24.2)$ & \\
\hline$\$ 100,000$ to $\$ 149,999$ & $32(21.8)$ & $12(23.1)$ & $20(21.1)$ & \\
\hline$\$ 150,000$ or more & $17(11.6)$ & $8(15.4)$ & $9(9.5)$ & \\
\hline Health Insurance, n (\%) & & & & 0.31 \\
\hline Medicare & $12(8.2)$ & $4(7.7)$ & $8(8.4)$ & \\
\hline Medicaid & $3(2.0)$ & $2(3.8)$ & $1(1.1)$ & \\
\hline Other government insurance & $10(6.8)$ & $6(11.5)$ & $4(4.2)$ & \\
\hline Private insurance & $117(79.6)$ & $38(73.1)$ & $79(83.1)$ & \\
\hline None/Private pay & $4(2.7)$ & $2(3.8)$ & $2(2.1)$ & \\
\hline Time of bariatric surgery, $\mathrm{n}(\%)$ & & & & 0.047 \\
\hline
\end{tabular}


Citation: Chan LN, Zheng Q, Colovos T. Assessing Micronutrient Adherence after Bariatric Surgery: An Exploratory Study. J Obes Bariatrics. 2015;2(2): 8.

ISSN: $2377-9284$

\begin{tabular}{|c|c|c|c|}
\hline In the past year & $126(85.7)$ & $41(78.8)$ & $7(13.5)$ \\
\hline 1 to 2 years ago & $11(7.5)$ & $1(1.9)$ & $3(4.2)$ \\
\hline 3 to 5 years ago & $6(4.1)$ & $5(5.3)$ \\
\hline 6 to 10 years ago & $4(2.7)$ & 0 & $1(1.0)$ \\
\hline More than 10 years ago & 0 & $46(88.5)$ & 0 \\
\hline Bariatric team recommended vitamin and mineral \\
supplementation, N (\%)
\end{tabular}

BMI: Body Mass Index; RYGB: Roux-en-Y Gastric Bypass; SG: Sleeve Gastrectomy

Sample sizes for characteristics vary due to missing responses and reflect numbers of respondents with available data.

aOne missing response in the RYGB group: total $n=146$; RYGB $n=51$; SG $n=95$.

${ }^{b}$ Available responses: total $n=145 ; R Y G B n=51 ; S G n=94.5$ respondents selected two race categories and were counted twice.

'Percentage (\%) calculated as $\mathrm{N}$ divided by the total number of respondents of each surgery type.

${ }^{\mathrm{d} A}$ Available responses: total $n=128$; RYGB $n=45$; SG $n=83$.

${ }^{\mathrm{e}} P$ values compare the two surgery groups and were obtained by unpaired t-test for parametric variables and Chi square test for categorical variables.

similar to average Americans. There were no significant differences among surgery groups in characteristics of respondents, except for race $(p=0.047)$.

\section{Postoperative micronutrient supplementation and adherence}

Of the 131 the patients responded that they had been advised to take vitamins and minerals postoperatively by their bariatric team, 125 (95.4\%) indicated that they remembered the specific micronutrient regimens as recommended by their care providers (Table 1). The mean self-reported adherence ranged between $68.4 \%$ and $100 \%$ for various micronutrients. Folic acid has the highest adherence rate (100\%), followed by vitamin D (96.4\%), vitamin C (93.3\%) and vitamin B12 (91.3\%). Calcium and iron supplements had the lowest overall adherence rate $(75.9 \%$ and $81.6 \%$, respectively) (Table 2$)$. The median and average daily doses of various supplements taken by the patients were summarized in Table 3 .

\section{Barriers to adherence}

Forty-eight percent of the patients identified at least one barrier for adhering to the micronutrient regimens as recommended by their providers. Table 4 summarized the reported barriers experienced by the 132 patients who answered this question. Forgetting the dose, side effects, and unpleasant taste were the top three barriers stated by the patients.

\section{Supplement purchase and choice}

In-person purchases at the local pharmacy, drugstore, nutritional supplement store, or convenience store represented the primary venues where the patients purchased their micronutrient supplements (Table 5). Interestingly, the most important factor in affecting their purchase was supplements with a "bariatric brand" or bariatric labeling (24.4\%), followed by the ingredients or products suggested by providers $(22.9 \%)$ and costs $(21.4 \%)$.

\section{Discussion}

Lifelong micronutrient supplementation is a crucial component of post-bariatric surgery care in order to achieve long-term success. This study offers unique insight into bariatric patients' perspectives on postoperative nutritional care, including barriers to adherence, and factors affecting the choices of micronutrient products. Our results showed that the recommendations on micronutrient supplementation provided by care providers to bariatric patients varied greatly. This finding is similar to results from two recently published studies $[7,8]$. Importantly, over half of the patients in our study did not adhere to the calcium, vitamin $\mathrm{D}$ and vitamin $\mathrm{B}_{12}$ regimens as recommended by the current guidelines [1].

Overall, the mean adherence rate for various micronutrient supplementations is comparable to that observed in the study with adolescent bariatric surgery patients by Modi et al. [5]. Similar to Modi's study as well as other investigations assessing medication adherence, we suspect this rate would further decrease over time [5,9-13]. This is concerning since the majority of the patients in this study had surgery within the past 12 months. It is very likely that the adherence rate for patients who had surgery for over 5 years postoperatively is much lower. This speculation is supported by the results from the study by Agaba et al. [8]. In a telephone survey in bariatric surgery from a single center, the micronutrient adhere rate declined every year with a 5 -year adhere rate of $4 \%$. Together with under-supplementation, the risk for having postoperative nutritionalrelated medical complications such as osteoporosis, anemia and neuropathy, is high.

The adherence rate varied among different supplements ranging from $68.4 \%$ to $100 \%$. Calcium and iron supplements had the lowest adherence. This is a concerning finding because along with insufficient vitamin D intake, these patients will have further increased risk to develop long-term complications such as chronic anemia and osteoporosis. We suspect that this is related to the costs and side 
Citation: Chan LN, Zheng Q, Colovos T. Assessing Micronutrient Adherence after Bariatric Surgery: An Exploratory Study. J Obes Bariatrics. 2015;2(2): 8.

ISSN: $2377-9284$

Table 2: Self-reported adherence rate to micronutrient supplementation.

\begin{tabular}{|c|c|c|c|}
\hline & All respondents ${ }^{a}$ & RYGB & SG \\
\hline Supplement Type & $\begin{array}{c}\text { Adherence rate, } \\
\%(\mathrm{n} / N)^{\mathrm{b}}\end{array}$ & $\begin{array}{c}\text { Adherence rate, } \\
\%(\mathrm{n} / N)^{\mathrm{b}}\end{array}$ & $\begin{array}{c}\text { Adherence rate, } \\
\%(\mathrm{n} / N)^{\mathrm{b}}\end{array}$ \\
\hline $\begin{array}{c}\text { Multivitamin + mineral } \\
\text { with Iron }\end{array}$ & $86.4(70 / 81)$ & $87.1(27 / 31)$ & $86.0(43 / 50)$ \\
\hline $\begin{array}{l}\text { Multivitamin + mineral } \\
\text { without iron }\end{array}$ & $88.9(24 / 27)$ & $100(14 / 14)$ & $76.9(10 / 13)$ \\
\hline Thiamin & $84.6(11 / 13)$ & $100(5 / 5)$ & $75.0(6 / 8)$ \\
\hline Folic acid & $100(8 / 8)$ & $100(4 / 4)$ & $100(4 / 4)$ \\
\hline Iron & $81.6(31 / 38)$ & $94.7(18 / 19)$ & $68.4(13 / 19)$ \\
\hline Vitamin C & $93.3(14 / 15)$ & $100(7 / 7)$ & $87.5(7 / 8)$ \\
\hline Calcium & $75.9(60 / 79)$ & $77.4(24 / 31)$ & $75.0(36 / 48)$ \\
\hline Vitamin D & $96.4(54 / 56)$ & $91.7(22 / 24)$ & $100(32 / 32)$ \\
\hline
\end{tabular}

RYGB: Roux-en-Y Gastric Bypass; SG: Sleeve Gastrectomy

aOnly included results from those who could specifically report the regimens recommended by care providers as well as the actual amount and frequency they were taking.

${ }^{\mathrm{b}} \mathrm{N}$ is the total number of respondents who were advised to take a micronutrient supplement and able to report both the recommendation and their actual consumption of the supplement. $\mathrm{n}$ is the number of respondents adherent to their supplement recommendation, defined as those who are taking the supplement exactly the as they were instructed or more than the recommended dose. Adherence rate was calculated by $(\mathrm{n} / \mathrm{N}) \times 100 \%$.

Table 3: Average and median dose of individual micronutrient supplements other than multivitamin and minerals taken by patients after bariatric surgery.

\begin{tabular}{|c|c|c|c|c|c|c|c|c|c|}
\hline \multirow[t]{2}{*}{$\begin{array}{l}\text { Supplement type } \\
\text { (dose per day*) }\end{array}$} & \multicolumn{3}{|c|}{ All patients } & \multicolumn{3}{|c|}{ RYGB } & \multicolumn{3}{|c|}{ SG } \\
\hline & $n$ & mean & median & $\mathrm{n}$ & mean & median & $\mathrm{n}$ & mean & median \\
\hline Vitamin C, mg/d & 12 & $2325^{a}$ & 750 & 6 & 650 & 500 & 6 & $4000^{a}$ & 1000 \\
\hline Calcium, mg/d & 61 & 1198 & 1000 & 28 & 1204 & 1000 & 33 & 1194 & 1200 \\
\hline Vitamin D, IU/d & 49 & $2911^{b+c}$ & 2000 & 21 & $2574^{b}$ & 2000 & 28 & $3163^{c}$ & 2000 \\
\hline \multicolumn{10}{|l|}{ Vitamin $\mathrm{B}_{12}$} \\
\hline $\mathrm{mcg} / \mathrm{d}$ & 70 & $782^{d}$ & 500 & 26 & 747 & 750 & 44 & $802^{\mathrm{d}}$ & 500 \\
\hline $\mathrm{mcg}$ shot/month & 2 & 1500 & & & & & 2 & 1500 & \\
\hline
\end{tabular}

LAGB: Laparoscopic Adjustable Gastric Banding; NA: Not Available; RYGB: Roux-en-Y Gastric Bypass; SG: Sleeve Gastrectomy; IU: International Units

a 1 respondent was taking $200 \%$ RDA for vitamin C $=75 \mathrm{mg} /$ day $\times 2$ for adult female; one was taking 10,000 mg twice a day, as an outlier.

b1 respondent was taking $50 \mathrm{IU} /$ day vitamin $\mathrm{D}$, one was taking 10,000 IU/day.

'3 respondents were taking 50,000 IU/week vitamin D, one was taking 10,000 IU/day.

dincludes oral and nasal spray, (1 spray $=500 \mathrm{mcg}$ cyanocobalamin). 2 respondents were taking $5,000 \mathrm{mcg} / \mathrm{day}$ orally.

${ }^{*}$ Current recommended intake: calcium citrate 1200-1500 mg/day; Vitamin D 3,000 IU/day; Vitamin B12 as needed for normal range.

Table 4: Barriers to adherence to micronutrient supplementations as identified by the respondents $(n=137)$

\begin{tabular}{|c|c|c|}
\hline & $\mathbf{N}$ & $\%$ \\
\hline \multicolumn{3}{|l|}{ Difficult to take recommended supplements, $N=132$} \\
\hline No & 69 & 52.3 \\
\hline Yes & 63 & 47.7 \\
\hline \multicolumn{3}{|l|}{ Barriers: } \\
\hline Forgetting & 26 & 41.3 \\
\hline Side effects & 13 & 20.6 \\
\hline Too expensive & 4 & 6.3 \\
\hline Difficult to find the recommended supplements & 2 & 3.2 \\
\hline Confused by care provider's instructions & 1 & 1.6 \\
\hline Othera: & 17 & 27.0 \\
\hline Unpleasant taste/flavor & 6 & 9.5 \\
\hline Chewing/swallowing difficulty & 4 & 6.3 \\
\hline Supplement timing issue & 3 & 4.8 \\
\hline
\end{tabular}

a Other barriers entered as free-text by more than one respondent. 
Citation: Chan LN, Zheng Q, Colovos T. Assessing Micronutrient Adherence after Bariatric Surgery: An Exploratory Study. J Obes Bariatrics. 2015;2(2): 8.

ISSN: $2377-9284$

Table 5: Micronutrient supplement purchase methods and choosing factors.

\begin{tabular}{|c|c|c|}
\hline & $n$ & $\%$ \\
\hline \multicolumn{3}{|l|}{ Ways to purchase supplements, $N=131$} \\
\hline Purchased as OTC supplements ${ }^{a}$ & 71 & 54.2 \\
\hline Purchased through the internet & 49 & 37.4 \\
\hline Purchased as prescription items & 6 & 4.6 \\
\hline Purchased from my physician & 3 & 2.3 \\
\hline Variety of methods & 2 & 1.5 \\
\hline \multicolumn{3}{|l|}{$\begin{array}{l}\text { Factors influencing supplement choices, } \\
\qquad N=131\end{array}$} \\
\hline Bariatric-branded supplements & 32 & 24.4 \\
\hline Products as recommended by care provider & 30 & 22.9 \\
\hline Costs & 28 & 21.4 \\
\hline Availability & 12 & 9.2 \\
\hline Recommended by support groups & 5 & 3.8 \\
\hline Other ${ }^{\mathrm{b}}$ : & 24 & 18.3 \\
\hline Vitamin/mineral composition of supplements & 7 & 5.3 \\
\hline Supplement forms & 7 & 5.3 \\
\hline Pill size/easy to swallow & 5 & 3.8 \\
\hline Organic/whole food based/other ingredients & 4 & 3.1 \\
\hline Flavor & 3 & 2.3 \\
\hline Personal research & 2 & 1.5 \\
\hline Brand reputation & 2 & 1.5 \\
\hline
\end{tabular}

OTC: Over-The-Counter

Sample sizes $(N)$ reflect numbers of patients responded to the specific questions.

alncludes pharmacy, drug store, nutritional supplement store, and convenience store

${ }^{\mathrm{b}}$ Other factors entered as free-text by more than one respondent

effect profile of these two minerals. For calcium supplements, most respondents reported taking calcium citrate, which is much more expensive than calcium carbonate. The preference for citrate is also likely associated with the impression that calcium citrate is better absorbed than calcium carbonate. However, clinical studies have not consistently demonstrated that calcium carbonate is inferior to calcium citrate with regard to oral bioavailability and long-term outcomes [14-22]. In a randomized, double-blind, crossover trial aimed to compare the absorption kinetics between calcium citrate and calcium carbonate (both provided $500 \mathrm{mg}$ of elemental calcium with 125 international units of vitamin D) in 18 patients with RYGB approximately 2 years prior (range 11 - 35 months), calcium citrate appeared to result in a statistically significantly higher serum calcium exposure within 6 hours of dose administration compared with calcium carbonate (6-hour area under the concentration-time curve [AUC] was $55 \pm 2$ vs $54 \pm 2 \mathrm{mg} / \mathrm{dL} \cdot \mathrm{h} ; p=0.02$ ) [23]. Nevertheless, the difference was very small and its clinical significance is doubtful. More importantly, despite a higher average AUC among the entire study cohorts, 9 of the 18 subjects actually achieved higher serum calcium AUC with the carbonate treatment arm [23]. This suggests that the oral bioavailability between the two calcium salt forms is highly patient-dependent. How the product is formulated may have a more important effect on bioavailability than the salt form alone [24].
Additionally, calcium carbonate is available as chewable tablets and provides twice the amount of elemental calcium than calcium citrate on a per gram basis ( $40 \%$ vs $21 \%$, respectively) [25]. Since a number of the patients in our study also reported having swallowing difficulty with calcium supplements because of the large doses (e.g. 4 calcium citrate tablets a day) and large tablet size, using calcium carbonate may improve adherence for some patients by decreasing costs and pill burden.

Our results showed that $21 \%$ of the patients stated side effect as a barrier to adherence (Table 4). Gastrointestinal (GI) side effects, such as nausea, constipation and dyspepsia, are well-documented with oral iron therapy. Research on iron supplementation tolerability and adherence has been primarily conducted in pregnant or postpartum women, in which adherence rates for iron have been found to be between $60-70 \%$ due to the side effects [26,27]. Ferrous sulfate is commonly used as the oral iron preparation because of its high elemental iron content (33\%), documented efficacy, low cost, and availability without a prescription $[1,28,29]$. A common practice is to use ferrous sulfate 300 to $325 \mathrm{mg}$ (providing approximately 65 $\mathrm{mg}$ of elemental iron) daily to three times a day to prevent or treat anemia. In this survey, we did not ask the patients to report the salt form of iron supplement they took; however, the reported frequency for iron supplement ranged from 1 to 4 tablets daily. This suggests that the majority of our patients were taking a regimen comparable to those in common practice. A dose-dependent effect of the amount of elemental iron on the GI tract has been described by Ekstrom et al. in which the incidence of GI side effects of $50 \mathrm{mg}$ vs. $120 \mathrm{mg}$ of elemental iron was $12 \%$ and $20 \%$, respectively [30]. Souza et al. also demonstrated a dose-related side effect profile for ferrous sulfate (60 $\mathrm{mg}$ once weekly vs. twice weekly vs. daily) [25]. If iron supplement is taken in addition to an iron containing multivitamin formulation, as over $50 \%$ of the patients in this study did, the likelihood of experiencing GI side effects becomes even higher which further increases the risk of non-adherence. Since the GI side effects are proportionate to the amount of elemental iron present in the GI tract lumen, and higher doses of iron are not necessarily associated with quicker and better clinical response and are poorly tolerated, reducing the dose of elemental iron may reduce the incidence and severity of GI side effects and improve adherence [31]. Options to improve adherence of iron supplementation may include increasing the daily frequency of supplementation rather than the dose, using heme-based iron products or other iron polymers which appear to have fewer GI side effects, and considering parenteral iron therapy in carefully selected patients.

Cost is another identified barrier to supplement adherence. The costs for micronutrient supplements are usually not covered by patient's insurance. Since the majority of our study patients purchased their supplements from their neighborhood grocery stores and pharmacies, we estimate that the average monthly out-ofpocket cost is between $\$ 15$ and $\$ 25$. This amount translates to $\$ 200$ to $\$ 300$ a year for vitamin and mineral supplements alone. Our results suggest that the most influential factor in determining the choice of products is having a bariatric branding on the products, which are more expensive than the generic supplements. So, the actual annual expenditure on micronutrient products may be over $\$ 500$. This can impose a substantial financial burden in the long run, especially 
Citation: Chan LN, Zheng Q, Colovos T. Assessing Micronutrient Adherence after Bariatric Surgery: An Exploratory Study. J Obes Bariatrics. 2015;2(2): 8.

among patients with lower income or unemployed due to disability or other obesity-related conditions, which further increases the risk of decreased adherence over time.

The finding that the bariatric-branded products are preferred by our respondents over the recommendation by their healthcare providers is of additional interest. Although these specialty products generally include fixed combinations of essential micronutrients to prevent clinical deficiency, the actual amount needed by a patient should be individualized based on factors such as diet, climate, physical findings and symptoms, drug-nutrient interactions, and laboratory results. Therefore, this may reflect a market success for specific manufacturers and may not have a direct positive impact on clinical outcomes. Furthermore, it raises the concern whether a communication gap or distrust may have existed between bariatric patients and their care providers regarding micronutrient management. Future studies should be directed towards assessing the communication and trust between patients and care providers.

There are several limitations to this study. Adherence to supplements was self-reported by patients through an online survey. The actual adherence rate therefore could be lower. The study patients were recruited through online community support groups for individuals undergoing bariatric surgeries, and thus the pool of respondents is limited to those who had the ability to use the internet and those being inherently motivated to manage their own health. The results from the SF-12 also suggested that the respondents' health is similar to that of the general U.S. population. Together with the high current employment rate and above median household income, a lower adherence rate is likely in the general bariatric patient population, especially amongst those with lower household income or Medicaid recipients. But since this study is of exploratory nature, we are using the findings to help design future investigations aimed to address more focused areas to increase micronutrient supplement adherence and maximize long-term safety of bariatric surgery as well as patient with other GI tract surgeries. Additionally, future studies should include bariatric patients who are at higher risk of nonadherence to postoperative micronutrient regimens, as well as those with higher risks for developing nutritional complications.

\section{Conclusion}

The short-term adherence rate for micronutrient supplementation varies among patients with recent bariatric surgery. Calcium and iron supplements are associated with the lowest adherence rate. The adherence rate is likely much lower over time, among patients with lower household incomes, and with worse chronic health. The major barriers affecting adherence include, forgetting, side effects, costs, and palatability of the products. Neighborhood retails store and internet were the primary venues where micronutrients were purchased. Successful marketing and branding of products by the manufacturers appeared to have a stronger influence on patient's decision on product selection than the recommendations by their care providers.

\section{References}

1. Mechanick JI, Youdim A, Jones DB, Garvey WT, Hurley DL, et al. (2013) Clinical practice guidelines for the perioperative nutritional, metabolic, and nonsurgical support of the bariatric surgery patient--2013 update: cosponsored by American Association of Clinical Endocrinologists, the
Obesity Society, and American Society for Metabolic \& Bariatric Surgery. Endocr Pract 19: 337-372.

2. Saif T, Strain GW, Dakin G, Gagner M, Costa R, et al. (2012) Evaluation of nutrient status after laparoscopic sleeve gastrectomy 1, 3, and 5 years after surgery. Surg Obes Relat Dis 8: 542-547.

3. Mercachita T, Santos Z, Limão J, Carolino E, Mendes L (2014) Anthropometric evaluation and micronutrients intake in patients submitted to laparoscopic Roux-en-Y gastric bypass with a postoperative period of $\geq 1$ year. Obes Surg 24: 102-108.

4. Gudzune KA, Huizinga MM, Chang HY, Asamoah V, Gadgil M, et al. (2013) Screening and diagnosis of micronutrient deficiencies before and after bariatric surgery. Obes Surg 23: 1581-1589.

5. Modi AC, Zeller MH, Xanthakos SA, Jenkins TM, Inge TH (2013) Adherence to vitamin supplementation following adolescent bariatric surgery. Obesity (Silver Spring) 21: E190-E195.

6. Maruish ME, Kosinski M (2009) A guide to the development of certified short form survey interpretation and reporting capabilities. Certified Scoring Guides, Quality Metric, Incorporated.

7. Dunstan MJ, Molena EJ, Ratnasingham K, Kamocka A, Smith NC, et al. (2015) Variations in oral vitamin and mineral supplementation following bariatric gastric bypass surgery: a national survey. Obes Surg 25: 648-655.

8. Agaba EA, Smith K, Normatov I, Singh A, Change S, et al. (2015) Post-gastric bypass vitamin therapy: how compliant are your patients and who is doing the monitoring? J Obes Bariatrics 2: 1-5.

9. Couzi L, Moulin B, Morin MP, Albano L, Godin M, et al. (2013) Factors predictive of medication nonadherence after renal transplantation: a French observational study. Transplantation 95: 326-332.

10. Jongen PJ, Hengstman G, Hupperts R, Schrijver H, Gilhuis J, et al. (2011) Drug adherence and multidisciplinary care in patients with multiple sclerosis: protocol of a prospective, web-based, patient-centred, nation-wide, Dutch cohort study in glatiramer acetate treated patients (CAIR study). BMC Neurol 11: 40 .

11. Liu X, Gelwicks S, Faries DE, Able SL (2010) Initial duloxetine prescription dose and treatment adherence and persistence in patients with major depressive disorder. Int Clin Psychopharmacol 25: 315-322.

12. Lucas GM, Gebo KA, Chaisson RE, Moore RD (2002) Longitudinal assessment of the effects of drug and alcohol abuse on HIV-1 treatment outcomes in an urban clinic. AIDS 16: 767-774

13. Godin G, Cote J, Naccache H, Lambert LD, Trottier S (2005) Prediction of adherence to antiretroviral therapy: a one-year longitudinal study. AIDS Care 17: 493-504.

14. Wang H, Bua P, Capodice J (2014) A comparative study of calcium absorption following a single serving administration of calcium carbonate powder versus calcium citrate tablets in healthy premenopausal women. Food Nutr Res 58.

15. Song YM, Sheu WH, Lee WJ (2001) Acute biochemical variations induced by calcium citrate and calcium carbonate in Type 2 diabetic patients: impaired calcium absorption in Type 2 diabetic patients with prolonged gastric emptying time. J Diabetes Complications 15: 97-102.

16. Hanzlik RP, Fowler SC, Fisher DH (2005) Relative bioavailability of calcium from calcium formate, calcium citrate, and calcium carbonate. J Pharmacol Exp Ther 313: 1217-1222.

17. Heller HJ, Poindexter JR, Adams-Huet B (2002) Effect of estrogen treatment and vitamin $\mathrm{D}$ status on differing bioavailabilities of calcium carbonate and calcium citrate. J Clin Pharmacol 42: 1251-1256.

18. Heaney RP, Dowell MS, Bierman J, Hale CA, Bendich A (2001) Absorbability and cost effectiveness in calcium supplementation. J Am Coll Nutr 20: 239246.

19. Hansen C, Werner E, Erbes HJ, Larrat V, Kaltwasser JP (1996) Intestinal calcium absorption from different calcium preparations: influence of anion and solubility. Osteoporos Int 6: 386-393.

20. Wood RJ, Serfaty-Lacrosniere C (1992) Gastric acidity, atrophic gastritis, and 
Citation: Chan LN, Zheng Q, Colovos T. Assessing Micronutrient Adherence after Bariatric Surgery: An Exploratory Study. J Obes Bariatrics. 2015;2(2): 8.

ISSN: $2377-9284$

calcium absorption. Nutr Rev 50: 33-40.

21. Harvey JA, Zobitz MM, Pak CY (1988) Dose dependency of calcium absorption: a comparison of calcium carbonate and calcium citrate. $\mathrm{J}$ Bone Miner Res 3: 253-258.

22. Heaney RP, Dowell MS, Barger-Lux MJ (1999) Absorption of calcium as the carbonate and citrate salts, with some observations on method. Osteoporos Int 9: 19-23.

23. Tondapu P, Provost D, Adams-Huet B, Sims T, Chang C, et al. (2009) Comparison of the absorption of calcium carbonate and calcium citrate after Roux-en-Y gastric bypass. Obes Surg 19: 1256-1261.

24. Sakhaee K, Pak C (2013) Superior calcium bioavailability of effervescent potassium calcium citrate over tablet formulation of calcium citrate after Roux-en-Y gastric bypass. Surg Obes Relat Dis 9: 743-748.

25. (2013) Calcium: Dietary supplement fact sheet. National Institutes of Health: Office of Dietary Supplements.
26. Souza Al, Batista Filho M, Bresani CC, Ferreira LO, Figueiroa JN (2009) Adherence and side effects of three ferrous sulfate treatment regimens on anemic pregnant women in clinical trials. Cad Saude Publica 25: 1225-1233.

27. Habib F, Alabdin EH, Alenazy M, Nooh R (2009) Compliance to iron supplementation during pregnancy. J Obstet Gynecol 29: 487-492.

28. Wax JR, Pinette MG, Cartin A, Blackstone J (2007) Female reproductive issues following bariatric surgery. Obstet Gynecol Surv 62: 595-604.

29. Marinella MA (2008) Anemia following roux-en-y surgery for morbid obesity: a review. South Med J 101: 1024-1031.

30. Ekström EC, Kavishe FP, Habicht JP, Frongillo EA Jr., Rasmussen KM, et al. (1996) Adherence to iron supplementation during pregnacy in Tanzania: determinants and hematologic consequences. Am J Clin Nutr 64: 368-374.

31. Chan LN, Mike LA (2014) The science and practice of micronutrient supplementations in nutritional anemia: an evidence-based review. JPEN J Parenter Enteral Nutr 38: 656-672 